\title{
Relationship between ventricular repolarization parameters and the inducibility of ventricular arrhythmias during electrophysiological study in patients with coronary artery disease
}

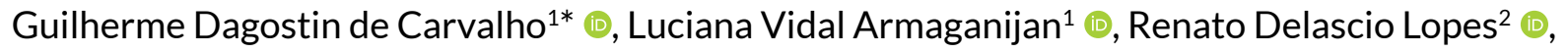

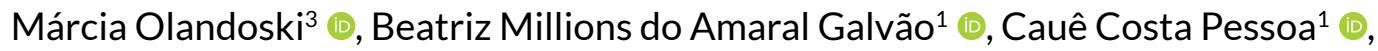

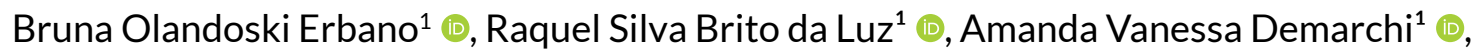 \\ Bruna Gomes de Medeiros ${ }^{1}$ (), Dalmo Antônio Ribeiro Moreira ${ }^{1}$ (])
}

\begin{abstract}
SUMMARY
OBJECTIVE: Risk stratification of sudden cardiac death in patients with coronary artery disease is of great importance. We evaluated the association between ventricular repolarization and induction of malignant ventricular arrhythmias on electrophysiological study of patients with coronary artery disease.

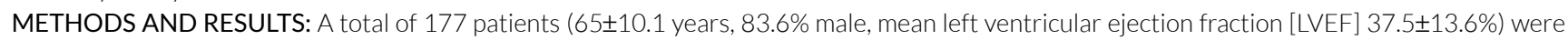
analyzed. For each 10 ms increment in the QT interval, there was a 7\% increase in malignant ventricular arrhythmias inducibility; QT cutoff point of $452 \mathrm{~ms}$ had an accuracy of 0.611 for predicting malignant ventricular arrhythmias ( $p=0.011$ ). Male gender (odds ratio [OR] $=4.18, p=0.012$ ), $L V E F$ $<35 \%(\mathrm{OR}=2.32, \mathrm{p}=0.013)$, amiodarone use $(\mathrm{OR}=2.01, \mathrm{p}=0.038)$, and prolonged $\mathrm{QT}(\mathrm{OR}=1.07, \mathrm{p}=0.023)$ were associated with malignant ventricular arrhythmias. In patients with ventricular dysfunction, QT >452 ms was associated with significantly increased risk of malignant ventricular arrhythmias $(\mathrm{OR}=5.44, \mathrm{p}=0.0004)$. In those with LVEF ${ }^{3} 35 \%$, QT dispersion (QTd) was significantly higher in patients with inducible malignant ventricular arrhythmias. QTd >20 ms had 0.638 accuracy and $81.3 \%$ negative predictive value in predicting malignant ventricular arrhythmias.

CONCLUSION: QT interval is an independent factor associated with malignant ventricular arrhythmias in patients with coronary artery disease. The combination of ventricular dysfunction and prolonged QT interval is associated with a 5.44-fold increase of malignant ventricular arrhythmias induction. Male gender, amiodarone use, and decreased left ventricular ejection fraction are also associated with increased risk of inducibility of malignant ventricular arrhythmias on the electrophysiological study.

KEYWORDS: Tachycardia, ventricular. Electrocardiography. Coronary artery disease. Death, sudden, cardiac.
\end{abstract}

\section{INTRODUCTION}

Up to $80 \%$ of sudden cardiac death (SCD) cases occur in patients with coronary artery disease (CAD). Strategies for the prevention of SCD include the use of antiarrhythmic agents and implantable cardioverter defibrillator (ICD). Left ventricular ejection fraction (LVEF) is the most commonly used parameter for risk stratification of SCD in patients with $\mathrm{CAD}^{1}$.

Abnormal ventricular repolarization has proven to be a marker of increased risk of malignant ventricular arrhythmias (MVA) and mortality in a variety of settings, including acute CAD, cardiomyopathies, hypertension, and Chagas disease ${ }^{2}$.

The aim of this study was to evaluate the association between electrocardiographic (ECG) ventricular repolarization and inducibility of MVA in patients with CAD undergoing electrophysiological study (EPS).

\section{METHODS}

This was a cross-sectional study of patients with CAD who underwent EPS in a tertiary hospital. CAD was defined by either history of acute coronary syndrome (ACS) or symptoms of angina and/or dyspnea on exertion associated with significant coronary lesions on cineangiocoronariography or myocardial ischemia on noninvasive examination. Patients with other cardiomyopathies and noninterpretable ECG within 6 months preceding EPS were excluded.

\footnotetext{
${ }^{1}$ Dante Pazzanese Institute of Cardiology - São Paulo (SP), Brazil.

${ }^{2}$ Duke Clinical Research Institute, Duke University Medical Center - Durham, USA.

${ }^{3}$ Pontifícia Universidade Católica do Paraná - Curitiba (PR), Brazil.

*Corresponding author: dagostinguilherme@gmail.com; guilherme.carvalho@dantepazzanese.org.br

Conflicts of interest: the authors declare there is no conflicts of interest. Funding: none.

Received on September 30, 2021. Accepted on October 08, 2021.
} 
CardioCalipers ${ }^{a}$ was used for ECG measurements. QT interval was measured in lead II using the tangent method; corrected QT interval (QTc) was calculated using Bazett's formula; QT dispersion (QTd) was obtained by the difference between the longest and shortest QT interval among all leads. The interval between the peak and the end of the $\mathrm{T}$ wave (Tp-e) was measured in V5 using the tangent method. The Tp-e dispersion (Tp-e d) was calculated by subtracting the longest and shortest Tp-e intervals in all leads; and for Tp-e/QT relationship calculation, both $\mathrm{Tp}$-e and QT were measured on the first beat of $\mathrm{VG}^{3}$.

EPS was performed as follows: programmed ventricular stimulation at two different sites with two basic cycles and up to three extra-stimuli. Rapid ventricular stimulation (up to 250 ms or until 2:1 ventricular capture) was also performed. Sustained ventricular tachycardia, ventricular flutter, and ventricular fibrillation (VF) were considered MVA, according to current guidelines definitions ${ }^{4}$.

Variables were presented by mean, standard deviation, median, and minimum/maximum values; categorical variables were presented by frequencies and percentages. MVA inducibility was compared with ECG parameters considering the model of analysis of variance (ANOVA) with one factor or Kruskal-Wallis nonparametric test.

For univariable analysis of factors associated with MVA induction, Fisher's exact test or chi-square test was used for categorical variables. For those with a quantitative character, we used Student's t-test for independent samples or MannWhitney nonparametric test. Normal condition of quantitative variables was assessed by Kolmogorov-Smirnov test.

For multivariable analysis, a logistic regression model was adjusted including variables with statistical significance in the univariable analysis. Wald's test was used to make decisions about the significance of the variables and the estimated association measure was odds ratio (OR) with 95\% confidence interval $(95 \% \mathrm{CI})$. For model validation, Hosmer-Lemeshow test was applied and the value of the area under the receiver operating characteristic (ROC) curve was estimated. A p-value $<0.05$ indicated statistical significance. Data were analyzed using Stata/SE version 14.1 (Stata Corp., LP, College Station, TX, USA) software.

\section{RESULTS}

A total of 182 consecutive patients met the inclusion criteria. Five of them were excluded due to noninterpretable ECG (three), Chagas disease (one), and hypertrophic cardiomyopathy (one).

Mean age was $65 \pm 10.1$ years, $83.6 \%$ were male, and mean LVEF was $37.5 \pm 13.6 \%$. The majority of patients $(76.8 \%)$ had history of ACS and previous aborted SCD occurred in 16.9\%. Among the comorbidities, hypertension (89.8\%), dyslipidemia (66.7\%), and diabetes mellitus (41.2\%) stood out. EPS was indicated for assessment of ventricular stability and syncope in 67.8 and $32.2 \%$ of cases, respectively (Table 1 ).

Table 1. Baseline clinical and demographic characteristics.

\begin{tabular}{|c|c|c|}
\hline Variable & Classification & Result \\
\hline Age (years) & & $65 \pm 10.1$ (35-94) \\
\hline \multirow{2}{*}{ Gender } & Male & $148(83.6)$ \\
\hline & Female & $29(16.4)$ \\
\hline Ejection fraction (\%) & & $37.5 \pm 13.6(18-75)$ \\
\hline \multirow{2}{*}{ Ejection fraction (\%) } & ${ }^{3} 35$ & $83(46.9)$ \\
\hline & $<35$ & $94(53.1)$ \\
\hline \multirow{4}{*}{ Previous ACS } & No & $41(23.2)$ \\
\hline & Unstable angina & $4(2.3)$ \\
\hline & NSTEMI & $45(25.4)$ \\
\hline & STEMI & $87(49.2)$ \\
\hline \multirow{5}{*}{ Angina } & No & $151(85.3)$ \\
\hline & $\operatorname{ccs} 1$ & $5(2.8)$ \\
\hline & $\operatorname{ccs} 2$ & $15(8.5)$ \\
\hline & $\operatorname{CCS} 3$ & $5(2.8)$ \\
\hline & $\operatorname{ccs} 4$ & $1(0.6)$ \\
\hline \multirow{5}{*}{ Intolerance on exertion } & No & $63(35.6)$ \\
\hline & NYHA I & $19(10.7)$ \\
\hline & NYHA II & $64(36.2)$ \\
\hline & NYHA III & $28(15.8)$ \\
\hline & NYHA IV & $3(1.7)$ \\
\hline \multirow{2}{*}{ Aborted SCD } & No & $147(83.1)$ \\
\hline & Yes & $30(16.9)$ \\
\hline Comorbidities & & $n(\%)$ \\
\hline Hypertension & & $159(89.8)$ \\
\hline Dyslipidemia & & $118(66.7)$ \\
\hline Diabetes mellitus & & $73(41.2)$ \\
\hline Syncope & & $56(31.6)$ \\
\hline $\begin{array}{l}\text { Chronic kidney } \\
\text { disease }\end{array}$ & & $34(19.2)$ \\
\hline Stroke or TIA & & 20 (11.3) \\
\hline $\begin{array}{l}\text { Peripheral artery } \\
\text { disease }\end{array}$ & & 20 (11.3) \\
\hline ICD carrier & & $4(2.3)$ \\
\hline Pacemaker carrier & & $3(1.7)$ \\
\hline Medications in use & & $n(\%)$ \\
\hline Statins & & $163(92.1)$ \\
\hline Aspirin & & $159(89.8)$ \\
\hline
\end{tabular}

Continue.. 
Table 1. Continuation.

\begin{tabular}{|c|c|c|}
\hline Variable & Classification & Result \\
\hline Beta-blockers & & $156(88.1)$ \\
\hline ACEi/ARBs & & $146(82.5)$ \\
\hline Furosemide & & $87(49.2)$ \\
\hline Amiodarone & & $73(41.2)$ \\
\hline Spironolactone & & $60(33.9)$ \\
\hline Nitrates & & $47(26.6)$ \\
\hline $\begin{array}{l}\text { Calcium channel } \\
\text { blockers }\end{array}$ & & 32 (18.1) \\
\hline $\begin{array}{l}\text { P2Y12 receptor } \\
\text { inhibitors }\end{array}$ & & $29(16.4)$ \\
\hline Oral anticoagulants & & $26(14.7)$ \\
\hline Hydralazine & & $9(5.1)$ \\
\hline Ivabradine & & $3(1.7)$ \\
\hline Trimetazidine & & $3(1.7)$ \\
\hline EPS indication & & $\mathrm{n}(\%)$ \\
\hline $\begin{array}{l}\text { Ventricular stability } \\
\text { assessment }\end{array}$ & & $120(67.8)$ \\
\hline $\begin{array}{l}\text { Previous documented } \\
\text { ventricular } \\
\text { arrhythmias }\end{array}$ & & 66 (37.3) \\
\hline Aborted SCD & & $30(17.0)$ \\
\hline Sustained VT & & $17(9.6)$ \\
\hline Nonsustained VT & & $19(10.7)$ \\
\hline $\begin{array}{l}\text { Absence of } \\
\text { previous ventricular } \\
\text { arrhythmias }\end{array}$ & & $54(30.5)$ \\
\hline Syncope & & $57(32.2)$ \\
\hline
\end{tabular}

ACS: acute coronary syndrome; NSTEMI: non-ST elevation acute myocardial infarction; STEMI: ST elevation acute myocardial infarction; CCS: Canadian Cardiovascular Society; NYHA: New York Heart Association; SCD: sudden cardiac death; TIA: transient ischemic attack; ICD: implantable cardioverter defibrillator; ACEi: angiotensin-converting enzyme inhibitor; ARBs: angiotensinreceptor blockers; EPS: electrophysiological study; VT:ventricular tachycardia.
In univariable analysis, male gender $(\mathrm{p}=0.03)$, low LVEF $(\mathrm{p}=0.01)$ (especially $<35 \% ; \mathrm{p}=0.033$ ), and amiodarone use $(\mathrm{p}=0.032)$ were associated with higher rates of MVA inducibility. QT interval was significantly longer in MVA induction group ( $\mathrm{p}=0.015)$.

In multivariable analysis, male gender $(\mathrm{OR}=4.37,95 \% \mathrm{CI}$ 1.1-12.6), LVEF <35\% (OR=2.25, 95\%CI 1.17-4.35), and QT interval (OR=1.07, 95\%CI 1.01-1.12) remained independent risk predictors of MVA. For each $10 \mathrm{~ms}$ increase in the QT interval, there was a 7\% increase in MVA inducibility.

QT interval of $452 \mathrm{~ms}$ was associated with $42.7 \%$ sensitivity, $79.4 \%$ specificity, $60.4 \%$ positive predictive value (PPV), and $65.3 \%$ negative predictive value (NPV) for MVA inducibility. Another model of logistic regression was performed using this cutoff point and all variables remained associated with the outcome (Table 2).

History of ACS was not found to be a predictor of MVA. In this subgroup of patients, QT interval remained associated with arrhythmic induction $(\mathrm{p}=0.013)$. In individuals without previous coronary events, there was no association between ECG variables and MVA. In patients with previous ACS, QT $>432 \mathrm{~ms}$ was associated with $55 \%$ sensitivity, $68 \%$ specificity, 57.9\% PPV, and 65.8\% NPV for MVA induction.

In individuals with $\mathrm{LVEF}<35 \%$, none of ECG parameters were related to arrhythmic inducibility on univariable analysis. When LVEF and QT interval variables were evaluated together, prolonged QT (>452 ms) and significant ventricular dysfunction increased the risk of MVA in 5.44-fold (Table 3).

In the subgroup of patients with LVEF ${ }^{3} 35 \%$, QTd was significantly higher in those with inducible MVA; such association was not verified in the other studied variables. QTd $>20 \mathrm{~ms}$ had an accuracy of 0.638 and $81.3 \%$ NPV in predicting MVA.

Table 2. Multivariable analysis of parameters associated with malignant ventricular arrhythmias induction on electrophysiological study using the cutoff indicated by the receiver operating characteristic curve.

\begin{tabular}{|c|c|c|c|c|}
\hline Variable & Classification & $\mathbf{p}^{*}$ & OR* & $95 \% \mathrm{Cl}$ \\
\hline \multirow{2}{*}{ Gender } & Female & & & \\
\hline & Male & 0.012 & 4.18 & $1.45-12.05$ \\
\hline \multirow{2}{*}{ Amiodarone use } & No & & & \\
\hline & Yes & 0.038 & 2.01 & $1.04-3.89$ \\
\hline \multirow{2}{*}{ Ejection fraction (\%) } & $\geq 35$ & & & \\
\hline & $<35$ & 0.013 & 2.32 & $1.20-4.48$ \\
\hline \multirow{2}{*}{$\mathrm{QT}^{\dagger}(\mathrm{ms})$} & $\leq 452$ & & & \\
\hline & $>452$ & 0.004 & 2.70 & $1.37-5.36$ \\
\hline
\end{tabular}

${ }^{*}$ Logistic regression model and Wald's test $(p<0.05) .{ }^{\dagger}$ Cutoff point indicated by the ROC curve. MVA: ventricular malignant arrhythmias; EPS: electrophysiological study; ROC: receiver operating characteristic; OR: odds ratio; 95\% CI: 95\% confidence interval. 
Table 3. Multivariable analysis of ventricular repolarization parameters in addition to left ventricular ejection fraction associated with ventricular malignant arrhythmias induction.

\begin{tabular}{|c|c|c|c|}
\hline Variable & $\mathbf{p}^{*}$ & $\mathrm{OR}^{*}$ & $95 \% \mathrm{Cl}$ \\
\hline LVEF $<35 \%$, QT $>452$ ms & 0.0004 & 5.44 & $2.13-12.89$ \\
\hline LVEF $\geq 35 \%$, QT $>452 \mathrm{~ms}$ & 0.064 & 2.59 & $0.95-7.08$ \\
\hline LVEF $<35 \%$, QT $\leq 452 \mathrm{~ms}$ & 0.12 & 1.82 & $0.86-3.86$ \\
\hline LVEF $\geq 35 \%, \mathrm{QT} \leq 452 \mathrm{~ms}^{\dagger}$ (reference) & - & - & - \\
\hline
\end{tabular}

*Logistic regression model and Wald's test $(\mathrm{p}<0.05)$. ${ }^{\dagger}$ Cutoff point indicated by the receiver operating characteristic curve. MVA: ventricular malignant arrhythmias; LVEF: left ventricular ejection fraction; OR: odds ratio; $95 \% \mathrm{Cl}$ : 95\% confidence interval; ROC: receiver operating characteristic.

\section{DISCUSSION}

Cardiovascular diseases (CVDs) are responsible for 17 million deaths annually worldwide, $25 \%$ of which result from SCD 5 . It is estimated that in the United States, between 300,000 and 350,000 cases of SCD occur annually, accounting for $50 \%$ of all deaths from $\mathrm{CV}$ etiology $y^{4}$.

Despite the advances in diagnostic strategies for risk stratification, depressed LVEF remains the best predictor of $S C D^{6,7}$. However, in adults aged $>35$ years, about two-third of SCD present as the first clinical event in individuals without previously identified heart disease or in patients with heart disease without other risk factors ${ }^{8}$.

The role of EPS in the risk stratification of SCD is relevant in the setting of CAD, especially in those with reduced LVEF and nonsustained VT in 24-h Holter monitoring. In these cases, MVA induction has a high $\mathrm{PPV}^{6}$. Wilber et al. demonstrated an incidence of SCD of $54 \%$ in 2 years in those with induced arrhythmias compared to $6 \%$ in the group with noninduced MVA'. Similarly, in the Multicenter Unsustained Tachycardia Trial, patients with CAD, LVEF $<40 \%$, and inducible MVA had higher rates of all-cause mortality ${ }^{10}$.

In this study, longer QT interval was associated with higher risk of MVA induction on EPS. Each $10 \mathrm{~ms}$ increase in the QT augmented in 7\% the risk of MVA. These findings are in agreement with the data published by Dekker et al. ${ }^{11}$, in which patients with prolonged QT had higher rates of CV death. Male gender was also associated with increased risk of MVA, and this finding is consistent with the data published by Schouten et al. ${ }^{12}$, who first demonstrated the value of QT in predicting mortality from CVD, especially CAD in men.

QT interval > $452 \mathrm{~ms}$ had moderate power to estimate MVA induction, similarly to that seen in a multicenter study, in which QT of $430 \mathrm{~ms}$ or more was associated with increased CV mortality ${ }^{13}$.

The use of amiodarone and LVEF $£ 35 \%$ were also related to MVA in the multivariable analysis. While the latter is a well-established predictor of SCD in the context of $\mathrm{CAD}^{1}$, the former may reflect the presence of ventricular arrhythmias despite drug treatment and, consequently, the greater severity of these patients.

QT prolongation in ACS is associated with spontaneous MVA, increased rates of SCD, and reduced survival in resuscitated patients from out-of-hospital VF. The magnitude of QT increase is related not only to the severity and extent of CAD but also to the depression of myocardial function, reflecting metabolic and electrolytic changes in ischemic tissue, hypoxemia, and autonomic nervous system imbalance ${ }^{14}$. In this study, in patients with previous ACS, QT interval was significantly longer in individuals with MVA. Similar finding was reported in the study by Schwartz and Wolf, in which longer QT was observed in those with acute myocardial infarction (AMI) compared to healthy persons $\mathrm{s}^{15}$. The cutoff point of $432 \mathrm{~ms}$ showed moderate predictive capacity in discriminating MVA induction in those with history of ACS. This finding is in agreement with a case-control study, in which QT $>440 \mathrm{~ms}$ in patients with previous AMI was associated with increased risk of $\mathrm{SCD}^{15}$.

Reduced LVEF is the main risk factor for general and sudden mortality in patients with CAD. Values $£ 40 \%$ are usually used to identify patients at high risk ${ }^{1,16,17}$. In our study, patients with QT $>452 \mathrm{~ms}$ and LVEF $<35 \%(\mathrm{p}=0.0003)$ presented higher incidence of inducible MVA. In the multivariable analysis, the combination of both parameters was an independent risk predictor for the outcome. Brendorp et al., in a multicenter trial, showed that individuals with ventricular dysfunction and QT $>479 \mathrm{~ms}$ had higher all-cause and CV mortality ${ }^{18}$. Similarly, in the study by Padmanabhan et al., patients with systolic dysfunction and QT $>450 \mathrm{~ms}$ had a mortality rate of $75 \%$ in 5 years compared to $52 \%$ in the group with QT $<450 \mathrm{~ms}^{19}$.

Finally, QTd $<20 \mathrm{~ms}$ had $78.6 \%$ sensitivity and $81.3 \%$ NPV to predict MVA, which denotes discriminatory capacity of patients at lower risk, a finding that is in line with that evidenced previously in a prospective study ${ }^{20}$.

Limitations of the study include cross-sectional and observational nature, inclusion of a single center, and use of MVA 
induction as a surrogate outcome to mortality. As a future perspective and clinical applicability, we highlight the fact of adding the QT interval as an ECG variable for predicting the risk of MVA in patients with CAD, a noninvasive and easily obtainable marker that adds strength of association, especially in those with LVEF $<35 \%$ and with previous ACS; additionally, in patients with LVEF $335 \%$, we highlight the high NPV of QTd, which allows discerning a subgroup of individuals at lower risk.

\section{CONCLUSIONS}

QT interval is an independent factor associated with MVA in patients with CAD. The combination of ventricular dysfunction

\section{REFERENCES}

1. Goldberger JJ, Cain ME, Hohnloser SH, Kadish AH, Knight BP, Lauer MS, et al. American Heart Association/American College of Cardiology Foundation/Heart Rhythm Society Scientific Statement on Noninvasive Risk Stratification Techniques for Identifying Patients at Risk for Sudden Cardiac Death. J Am Coll Cardiol. 2008;52(14):1179-99. https://doi.org/10.1016/j. jacc.2008.05.003

2. Castro-Torres Y. Ventricular repolarization markers for predicting malignant arrhythmias in clinical practice. World J Clin Cases. 2015;3(8):705. https://doi.org/10.12998/wjcc.v3.i8.705

3. Gupta P, Patel C, Patel H, Narayanaswamy S, Malhotra B, Green JT, et al. Tp-e/QT ratio as an index of arrhythmogenesis. J Electrocardiol. 2008;41(6):567-74. https://doi.org/10.1016/j. jelectrocard.2008.07.016

4. Al-Khatib SM, Stevenson WG, Ackerman MJ, Bryant WJ, Callans DJ, Curtis AB, et al. 2017 AHA/ACC/HRS Guideline for Management of Patients With Ventricular Arrhythmias and the Prevention of Sudden Cardiac Death: A Report of the American College of Cardiology/American Heart Association Task Force on Clinical Practice Guidelines and the Heart Rhythm Society. Circulation. 2018;138(13):e210-71. https://doi.org/10.1161/ CIR.0000000000000549

5. Mendis S, Puska P, Norrving B, World Health Organization, World Heart Federation, World Stroke Organization, editors. Global atlas on cardiovascular disease prevention and control. Geneva: World Health Organization in collaboration with the World Heart Federation and the World Stroke Organization; 2011. p. 155.

6. Saba S. Sudden cardiac death risk stratification and assessment: primary prevention based on ejection fraction criteria. Heart Fail Clin. 2011;7(2):175-83, vii. https://doi.org/10.1016/j.hfc.2010.12.004

7. Dagres N, Hindricks G. Risk stratification after myocardial infarction: is left ventricular ejection fraction enough to prevent sudden cardiac death? Eur Heart J. 2013;34(26):1964-71. https://doi. org/10.1093/eurheartj/eht109

8. Myerburg RJ. Sudden Cardiac Death: Exploring the Limits of Our Knowledge. J Cardiovasc Electrophysiol. 2001;12(3):369-81. https://doi.org/10.1046/j.1540-8167.2001.00369.x and prolonged QT interval is associated with a 5.44-fold increase of MVA induction. Male gender, amiodarone use, and decreased LVEF are also associated with increased risk of inducibility of MVA on the EPS.

\section{AUTHORS' CONTRIBUTIONS}

GDC: Project design, data collection, manuscript writing and review. LVA: Project design, manuscript writing and review. RDL: Manuscript review. MO: Statistical analysis. BMAG, CCP, BOE, RSBL, AVD, and BGM: Data collection and manuscript review. DARM: Project design and manuscript review.

9. Wilber DJ, Olshansky B, Moran JF, Scanlon PJ. Electrophysiological testing and nonsustained ventricular tachycardia. Use and limitations in patients with coronary artery disease and impaired ventricular function. Circulation. 1990;82(2):350-8. https://doi.org/10.1161/01. cir.82.2.350

10. Buxton AE, Lee KL, Hafley GE, Wyse DG, Fisher JD, Lehmann $\mathrm{MH}$, et al. Relation of Ejection Fraction and Inducible Ventricular Tachycardia to Mode of Death in Patients With Coronary Artery Disease: An Analysis of Patients Enrolled in the Multicenter Unsustained Tachycardia Trial. Circulation. 2002;106(19):2466 72. https://doi.org/10.1161/01.cir.0000037224.15873.83

11. Dekker JM, Crow RS, Hannan PJ, Schouten EG, Folsom AR. Heart rate-corrected QT interval prolongation predicts risk of coronary heart disease in black and white middle-aged men and women. $J$ Am Coll Cardiol. 2004;43(4):565-71. https://doi.org/10.1016/j. jacc.2003.09.040

12. Schouten EG, Dekker JM, Meppelink P, Kok FJ, Vandenbroucke JP Pool J. QT interval prolongation predicts cardiovascular mortality in an apparently healthy population. Circulation. 1991;84(4):151623. https://doi.org/10.1161/01.cir.84.4.1516

13. Elming H, Holm E, Jun L, Torp-Pedersen C, Køber L, Kircshoff $M$, et al. The prognostic value of the $Q T$ interval and $Q T$ interval dispersion in all-cause and cardiac mortality and morbidity in a population of Danish citizens. Eur Heart J. 1998;19(9):1391-400. https://doi.org/10.1053/euhj.1998.1094

14. Davey P. QT interval and mortality from coronary artery disease. Prog Cardiovasc Dis. 2000;42(5):359-84. https://doi.org/10.1053/ pcad.2000.0420359

15. Schwartz PJ, Wolf S. QT interval prolongation as predictor of sudden death in patients with myocardial infarction. Circulation. 1978;57(6):1074-7. https://doi.org/10.1161/01.cir.57.6.1074

16. Bigger JT, Fleiss JL, Kleiger R, Miller JP, Rolnitzky LM. The relationships among ventricular arrhythmias, left ventricular dysfunction, and mortality in the 2 years after myocardial infarction. Circulation. 1984;69(2):250-8. https://doi.org/10.1161/01. cir.69.2.250

17. The Multicenter Postinfarction Research Group. Risk Stratification and Survival after Myocardial Infarction. N Engl J Med. 1983;309(6):331-6. https://doi.org/10.1056/ NEJM198308113090602 
18. Brendorp B, Elming H, Jun L, Køber L, Malik M, Jensen GB, et al. Qtc interval as a guide to select those patients with congestive heart failure and reduced left ventricular systolic function who will benefit from antiarrhythmic treatment with dofetilide. Circulation. 2001;103(10):1422-7.https://doi.org/10.1161/01.cir.103.10.1422

19. Padmanabhan S, Silvet H, Amin J, Pai RG. Prognostic value of QT interval and QT dispersion in patients with left ventricular systolic dysfunction: results from a cohort of 2265 patients with an ejection fraction of $\leq 40 \%$. Am Heart J. 2003;145(1):132-8. https://doi. org/10.1067/mhj.2003.59

20. Bogun F, Chan KK, Harvey M, Goyal R, Castellani M, Niebauer M, et al. QT dispersion in nonsustained ventricular tachycardia and coronary artery disease. Am J Cardiol. 1996;77(4):256-9. https:// doi.org/10.1016/s0002-9149(97)89389-7 